\title{
Voice Function and Voice-Related Quality of Life in the Elderly
}

\author{
Sophie Schneider Christoph Plank Ulrich Eysholdt Anne Schützenberger \\ Frank Rosanowski \\ Department of Phoniatrics and Pedaudiology, Erlangen University Hospital, Erlangen, Germany
}

\section{Key Words}

Voice $\cdot$ Elderly • Quality of life • Dysphonia Severity Index

\begin{abstract}
Background: Many studies have referred to the effects of age on voice and the consequences of these changes. However, only little is known about the adverse effects of voice changes on quality of life in the elderly. Objective: This study focuses on self-perception of voice in seniors as assessed by the Voice-Related Quality of Life (V-RQOL) questionnaire, on voice quality as measured by the Dysphonia Severity Index (DSI) and on the correlation between these parameters. Methods: V-RQOL and DSI were measured as previously described in 107 non-treatment-seeking test persons without voice complaints (76 women and 31 men; mean age $78.7 \pm$ 6.8 years, range 66-94 years). Results: The mean V-RQOL value was $94.4 \pm 9.8 \%$. The mean value of the DSI in all participants was $1.2 \pm 2.4$. There was no significant correlation between the V-RQOL and DSI, either in women $(p=0.11)$, men $(p=0.58)$ or the whole study group $(p=0.26)$. Conclusion: Both the V-RQOL questionnaire and the DSI may be applied to seniors. As self-perception of voice and voice function do not correlate, both parameters have to be measured for voice assessment.

Copyright $\odot 2010$ S. Karger AG, Basel
\end{abstract}

(C) 2010 S. Karger AG, Basel

0304-324X/11/0572-0109\$38.00/0

Fax +4161306 1234

E-Mail karger@karger.ch

www.karger.com
Accessible online at: www.karger.com/ger

\section{Introduction}

Old age may affect the voice, with changes in vocal pitch, loudness and quality being the most relevant [1]. These changes are caused both by modification of laryngeal structures, such as atrophy and degeneration of laryngeal muscles, atrophy of mucous glands, stiff cartilages and joints, and physiologic age-related changes of more general functions, such as respiratory limitation, cardiovascular problems, skeletal and muscular changes, hormonal fluctuation and neurological disorders [2-5]. At present there is no consensus on when to classify these changes as a disease, e.g. dysphonia in the elderly or presbyphonia [6-11], or as normal, i.e. without medical consequences [5].

As voice changes in seniors may be regarded as multidimensional, in cases of complaints, therapy must also cover different aspects $[7,11,12]$. According to Sataloff et al. [12], 'in treating age related dysphonia, we combine traditional voice therapy, singing training, acting voice techniques and aerobic conditioning to optimize neuromuscular performance'. However, phonosurgery may be indicated in selected cases, such as professional voice use with age modifications refractory to other kinds of therapy $[7,12]$.

Surprisingly, little is known about the adverse effects of voice changes on quality of life in the elderly. However, it is assumed that they may cause a tendency to avoid so- 
cial gatherings and deterioration of self-esteem [13]. The lack of more data may be at least partly due to methodological shortcomings with regard to the question of how to measure self-perception of voice. According to the recommendations of the European Laryngological Society [14], voice assessment comprises not only laryngeal morphology and voice function but self-perception of voice changes as well. However, there is currently no consensus on how to measure this self-perception. At present, the Voice Handicap Index (VHI) questionnaire is regarded as the gold standard [14-18]. For German-speaking individuals, the results of the shorter Voice-Related Quality of Life (V-RQOL) questionnaire are equivalent [18-22].

Thus, this study focuses on (1) voice-related quality of life in seniors without voice complaints and not seeking voice treatment, (2) voice quality as assessed by the Dysphonia Severity Index (DSI) and (3) the question of interaction between these 2 parameters.

\section{Participants and Methods}

\section{Participants}

German-speaking adults $\geq 65$ years of age were recruited from senior community centers, senior meetings and assisted living facilities. Those currently receiving voice-related medical treatment, in need of skilled nursing care and/or with relevant cognitive limitations (e.g. dementia) were excluded from the study; the Mini-Mental State Examination was used to identify those with a cutoff value of 24 [23].

In total, 107 voluntary participants were included in the study after obtaining informed consent. Mean age was $78.7 \pm 6.8$ years (range 66-94; normally distributed). There were 76 females with a mean age of $78.7 \pm 7.3$ years (range 66-94) and 31 males with a mean age of $78.7 \pm 5.5$ years (range $67-88$; fig. 1 ).

\section{Methods}

Voice-related quality of life was assessed by the German version of the 10-item V-RQOL questionnaire [19]. Each item can be rated from 1 ('not a problem') to 5 ('a problem as bad as it can be'). The total score was calculated for all test persons according to the original test instructions $[19,20,22]$. It can range from 0 to $100 \%$, with high values indicating high voice-related quality of life.

The DSI is a calculation of different voice measurements which express the degree of voice problems, i.e. highest frequency (in hertz), lowest intensity (in decibels), maximum phonation time (in seconds) and jitter (as a percentage) [24, 25]. For analysis, voices were recorded as previously described [26]. This study refers to the graduation of the DSI established by Nawka and Wirth [27] (fig. 2).

For statistical analysis, the commercially available software packages Matlab ${ }^{\circledR}$ Software release 7.6 and Microsoft Excel ${ }^{\circledR} 2003$ were used. Normal distribution of age was proved by applying the Kolmogorov-Smirnov test. Spearman's algorithm was used for correlation analysis. Differences between gender groups were analyzed using the $t$ test. A $p$ value of $\leq 0.05$ was assumed to be statistically significant.

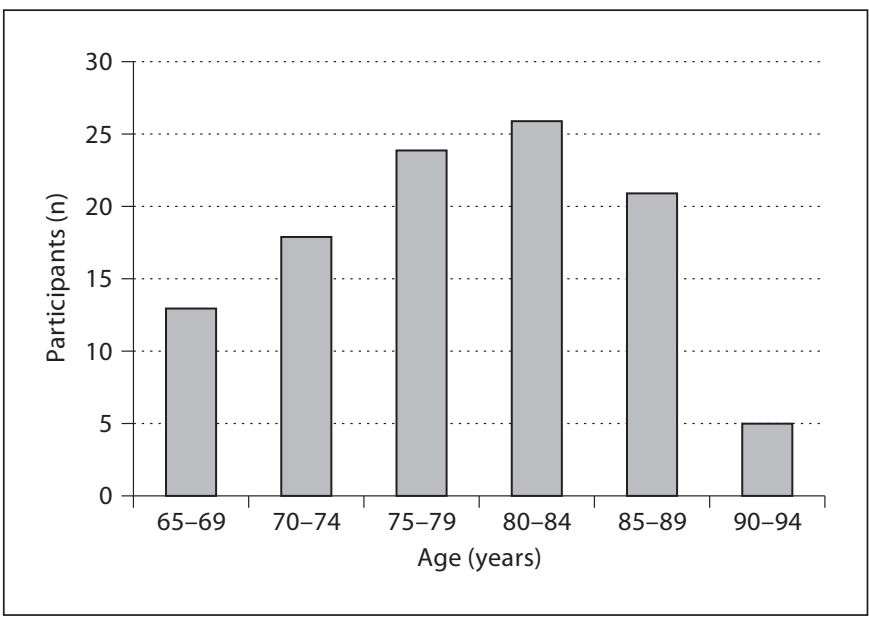

Fig. 1. Age distribution of our study participants.

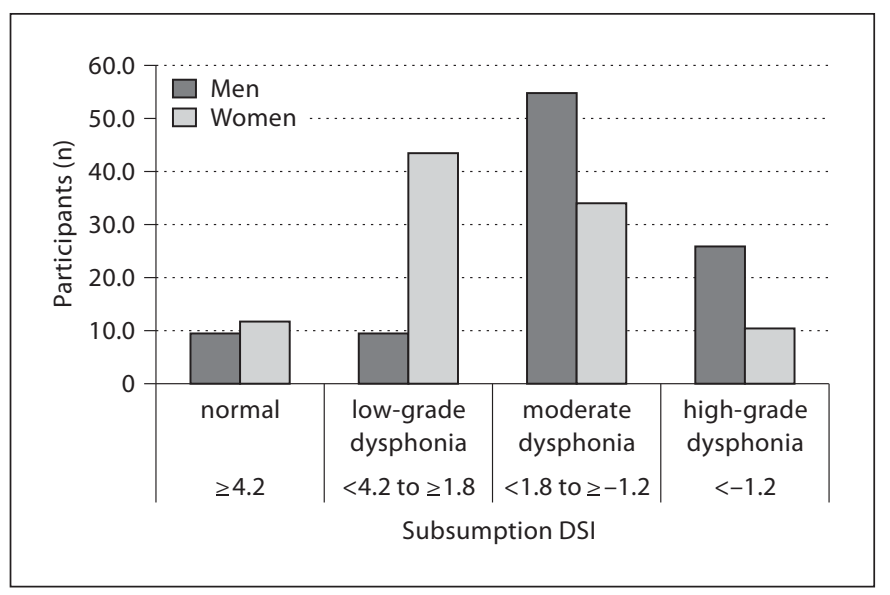

Fig. 2. DSI categorization of 107 elderly persons without voice complaints (arrangement according to Nawka and Wirth [27]), comparing women and men.

\section{Results}

The mean total score on the V-RQOL questionnaire was $95.6 \pm 7.9 \%$ in women and $91.6 \pm 12.8 \%$ in men (fig. 3). These results do not differ at a statistically significant level $(p=0.06)$. The mean total V-RQOL score of all participants was $94.4 \pm 9.8 \%$. No age dependence was found $(\mathrm{p}=0.32)$.

The DSI value was $1.6 \pm 2.1$ in women and $0.2 \pm 2.6$ in men (fig. 4). These values differ at a statistically significant level ( $p=0.01$; fig. 2 ). The mean DSI value of all 
Fig. 3. V-RQOL [19] results in 107 elderly persons without voice complaints.

Fig. 4. DSI [24] results in 107 elderly persons without voice complaints.
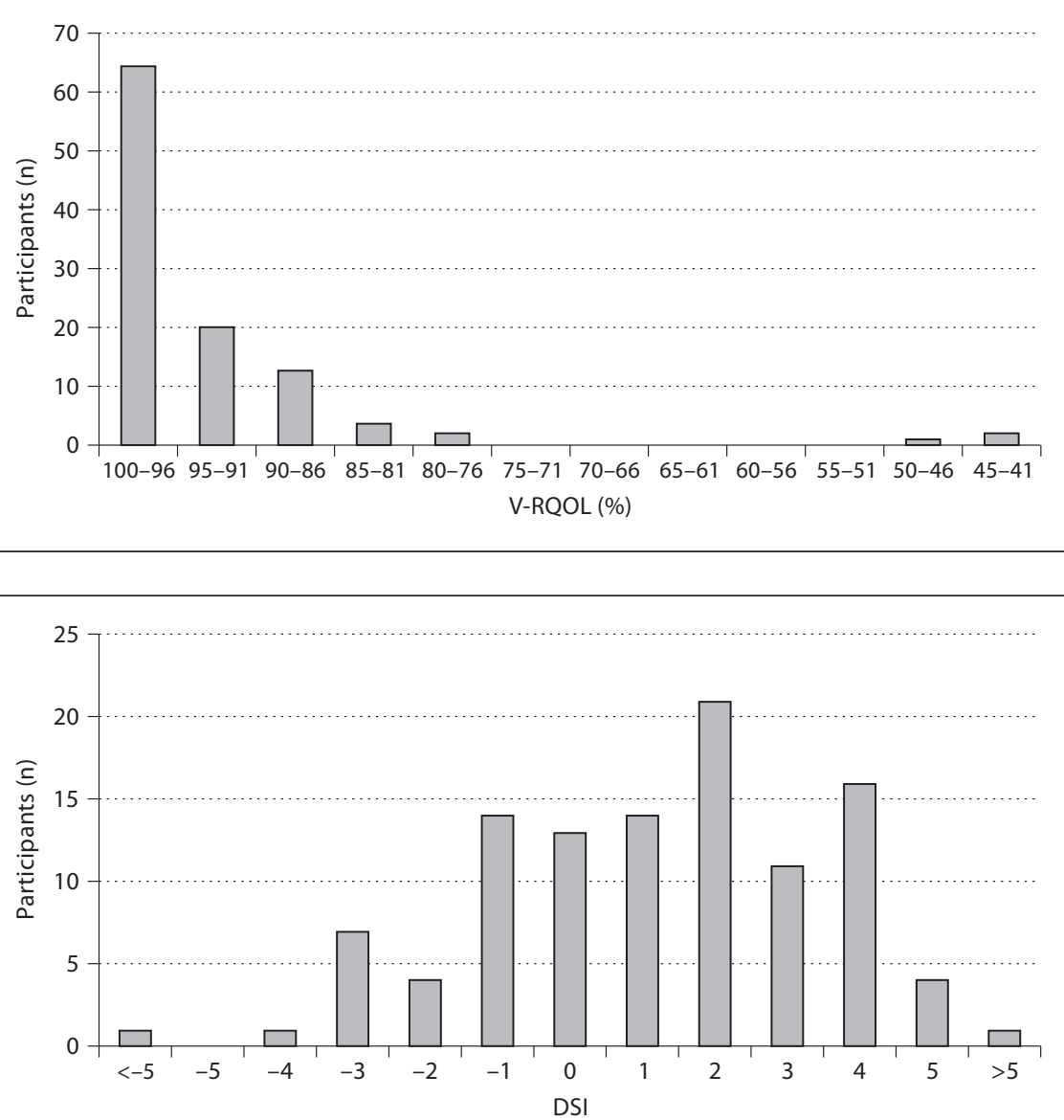

participants was $1.2 \pm 2.4$. The DSI was independent of age $(\mathrm{p}=0.26)$.

Comparing the V-RQOL and the DSI, there was no significant correlation between these parameters, either in women $(\mathrm{p}=0.11)$, in men $(\mathrm{p}=0.58)$ or in the entire study group $(\mathrm{p}=0.26)$; nor was there correlation when the participants were divided into age groups $(\mathrm{p}=0.47$ for the $65-74$ years age group; $\mathrm{p}=0.53$ for the $75-84$ years age group; $\mathrm{p}=0.55$ for the $85-94$ years age group).

\section{Discussion}

Contemporary society is a society of communication $[28,29]$, with voice being the parameter focused on in this study. The increasing number of elderly people in Western societies gives cause for scientific medical interest in voice assessment and evaluation in this age group in particular [6-12].

Voice Function in the Elderly
The gold standard for self-assessment of voice is the VHI, a 30-item questionnaire examining functional, physical and emotional aspects of voice disorders [14-18]. An alternative is the V-RQOL questionnaire [18-22], which gives almost identical results [21]. The latter is recommended for clinical application as it only comprises 10 items, while the VHI consists of 30 questions, and it is considered more practicable [18, 20]. Furthermore, Golub et al. [6] proved that the V-RQOL may be used in elderly patients. Hence, it was applied in the present study. The DSI served as an assessment tool for voice function [24, 25]. Results 'usually' range between -5 (very hoarse) and +5 (very good). The DSI has a nearly straight course [25]. It is a valid instrument to distinguish between pathological and nonpathological voices $[24,25]$ and has been proven to be appropriate for clinical purposes [30-33].

The age cutoff was set at 65 years, in accordance with the present statutory retirement age in Germany, because retirement is typically associated with various changes in 
daily activities $[34,35]$ and in communicative requirements. The participants were recruited from urban community centers and senior meetings in order to enrol 'active' and 'vigorous' people who still take part in social life and use their voice. Progressive immobility because of different diseases obstructs many of the $65+$ seniors from continuing their social life. The Mini-Mental State Examination [23] was used to ensure that test instructions and the questionnaire were understood by all participants, because the prevalence of dementia increases in persons older than 65 years. Thus, the study group may not be an entirely representative cross section of the 65+ subpopulation in Germany. However, at least the gender distribution reflects the larger German $65+$ population [35].

In previous studies, $\mathrm{V}$-RQOL results depended on age $[36,37]$ and gender $[36,38]$. This could not be proven in this study, as neither gender $(\mathrm{p}=0.06)$ nor age $(\mathrm{p}=0.32)$ correlated with V-RQOL results at a significant level. On the one hand, this difference may be due to the fact that those former studies focused on patients, whereas the present study deals with a non-treatment-seeking population. On the other hand, test persons over 65 show different results to a younger or mixed-age population; Murry et al. [38] reported that the severity of a voice disorder and voice-related quality of life correlate more clearly in participants younger than 66 than in persons over 66. So in fact, data obtained in this study are not comparable with those previously presented.

Furthermore, the V-RQOL results of women were previously found to be worse than those of men $[36,38]$. In this study, the results in women and men did not differ at a significant level. This again is mainly due to differences in study groups. So, further studies should investigate elderly persons with voice problems and compare their voice-related quality of life with those of younger dysphonic patients.

Nearly all seniors in this study had high V-RQOL values (fig. 3). According to the validation study presented by Hogikyan and Sethuraman [19] on the basis of data obtained in a clinical cohort, V-RQOL outcomes may be categorized into 3 levels. In addition to the V-RQOL, patients were asked to give a self-rating of their voice (poor, fair, good, very good, excellent). Comparing both, the VRQOL results could be grouped into 'poor/fair' (V-RQOL $53.1 \pm 22.4 \%$ ), 'good' (V-RQOL $83.1 \pm 15.3 \%$ ) and 'excellent/very good' (V-RQOL $95.0 \pm 8.7 \%$ ). In the present study, $95 \%$ of the test persons were in the highest category of 'excellent/very good', with values of $94.4 \pm 9.8 \%$. In a previous study from our group [39], 3 categories could be identified with health-related quality of life as external criterion; according to those cutoff values, $97 \%$ of the VRQOL values in the present study may be classified as 'normal' (V-RQOL values over $80 \%)$. However, at present there is no consensus on how to classify V-RQOL results, but even against the background of this restriction, the number of non-treatment-seeking persons achieving the best results in the present study does not differ much using the different classification systems.

The DSI showed varying results in previous studies. In one study [40], it did not depend on gender $(p<0.01)$, in contrast to the results obtained in this work $(\mathrm{p}=0.01)$ with higher values in women (fig. 2). With regard to the DSI, Hakkesteegt et al. [40] showed a significant effect of age, especially in women $(\mathrm{p}<0.01)$. In the present study, this could not be reproduced ( $p=0.26$ ). Maybe this is again due to differences in study groups (age, voice pathology, non-treatment-seeking participants). Thus, in fact, more data are necessary. Moreover, it should be considered that the DSI does not make a distinction between young and old voices. In its calculation, age is disregarded. This could also have an effect on the results of the current study and should be taken into account in further studies, especially in clinical cases.

A normal value of DSI would be +1 and a very good value +5 [25]. The seniors in this study had nearly normal values, with women having a mean DSI outcome of $1.6 \pm$ 2.1 , but men having a mean DSI value of $0.2 \pm 2.6$. Hence, overall the outcome of the DSI in the whole study group was moderately good.

Compared to the high results of the V-RQOL, it is surprising that the results of the DSI are only mediocre. In some studies, the severity of voice dysfunction and VRQOL correlated [21, 38, 41]. According to Wuyts et al. [24], the severity of a voice dysfunction and DSI values correlate. In this study, the results of the 2 assessment tools did not correlate $(p=0.26)$, perhaps because the study group was dominated by elderly people, in contrast to the younger groups in previous studies. Recent data from our group [42] showed similar results, i.e. absence of a correlation between V-RQOL and DSI in test persons with benign dysphonia $(\mathrm{p}>0.5)$. Using different voice parameters, for example the Roughness, Breathiness, Hoarseness scale, other outcomes could be shown; VRQOL and the Roughness, Breathiness, Hoarseness scale correlate at a significant level $(p<0.05)$ [43]. Thus, it is far from certain that different voice assessment tools correlate similarly to quality of life, which shows the necessity of further evaluation of methods applied for voice assessment. 
Voice changes in the elderly do not necessarily emerge suddenly. Thus, maybe the changes are not noticed easily, especially in elderly people, most of whom are retired and for whom voice may not be as important as during professional voice use [13]. Moreover, it is possible that elderly people do not notice the changes in their voice as much as other physical changes.
The present study allows for the following conclusion: as voice function and self-perception of voice do not correlate, both parameters have to be assessed specifically, both in young and elderly persons. Both the V-RQOL questionnaire and the DSI are applicable in seniors.

\section{References}

1 Mueller PB: The aging voice. Semin Speech Lang 1997;18:159-169.

2 Seidner W, Eysholdt U: Diagnostik; in Wendler J, Seidner W, Eysholdt U (eds): Lehrbuch der Phoniatrie und Pädaudiologie. Stuttgart, Thieme, 2005, p 94.

3 Boone DR: The three ages of voice: the singing/acting voice in the mature adult. J Voice 1997;11:161-164.

4 Ramig L, Gray S, Baker K, Corbin-Lewis K, Buder E, Luschei E, Coon H, Smith M: The aging voice: a review, treatment data and familial and genetic perspectives. Folia Phoniatr Logop 2001;53:252-265.

5 Sataloff RT, Rosen DC, Hawkshaw M, Spiegel JR: The three ages of voice: the aging adult voice. J Voice 1997;11:156-160.

6 Golub J, Chen P, Otto K, Hapner E, Johns M III: Prevalence of perceived dysphonia in a geriatric population. J Am Geriatr Soc 2006; 54:1736-1739.

7 Hagen P, Lyons G, Nuss D: Dysphonia in the elderly: diagnosis and management of agerelated voice changes. South Med J 1996;89: 204-207.

-8 Kandogan T, Olgun L, Gultekin G: Causes of dysphonia in patients above 60 years of age. Kulak Burun Bogaz Ihtis Derg 2003;11:139143.

9 Roy N, Stemple J, Merrill R, Thomas L: Epidemiology of voice disorders in the elderly: preliminary findings. Laryngoscope 2007; 117:628-633.

10 Woo P, Casper J, Colton R, Brewer D: Dysphonia in the aging: physiology versus disease. Laryngoscope 1992;102:139-144.

-11 Berg E, Hapner E, Klein A, Johns M III: Voice therapy improves quality of life in age-related dysphonia: a case-control study. J Voice 2008;22:70-74.

12 Sataloff RT, Spiegel JR, Rosen DC: The effects of age on the voice; in Sataloff R (ed): Professional Voice: The Science and Art of Clinical Care. San Diego, Singular Publishing Group, 1997, pp 259-267.

13 Verdonck-de Leeuw I, Mahieu H: Vocal aging and the impact on daily life: a longitudinal study. J Voice 2004;18:193-202.
4 Dejonckere PH, Bradley P, Pais C, Cornut G, Crevier-Buchman L, Friedrich G, Van De Heyning P, Remacle M, Woisard V: A basic protocol for functional assessment of voice pathology, especially for investigating the efficacy of (phonosurgical) treatments and evaluating new assessment techniques: guideline elaborated by the Committee on Phoniatrics of the European Laryngological Society (ELS). Eur Arch Otorhinolaryngol 2001;258:77-82.

15 Jacobsen BH, Johnson A, Grywalski C: The Voice Handicap Index (VHI): development and validation. Am J Speech Lang Pathol 1997;6:66-70.

16 Murry T, Rosen CA: Occupational voice disorders and Voice Handicap Index: patients' self-perception of their voice problems. Pan European Voice Conference III, Utrecht, August 1999.

17 Grässl E, Hoppe U, Rosanowski F: Grading of the Voice Handicap Index (in German). HNO 2007;56:1221-1228.

18 Günther S, Rasch T, Klotz M, Hoppe U, Eysholdt U, Rosanowski F: Bestimmung der subjektiven Beeinträchtigung durch Dysphonien. Ein Methodenvergleich. HNO 2005;53:895-904.

19 Hogikyan ND, Sethuraman G: Validation of an instrument to measure voice-related quality of life (V-RQOL). J Voice 1999;13: 557-569.

20 Hogikyan ND, Rosen CA: A review of outcome measurements for voice disorders. Otolaryngol Head Neck Surg 2002;126:562572.

21 Portone CR, Hapner ER, McGregor L, Otto K, Johns MM: Correlation of the Voice Handicap Index (VHI) and the Voice-Related Quality of Life Measure (V-RQOL). J Voice 2007;21:723-727.

22 Seidner W, Eysholdt U: Diagnostik; in Wendler J, Seidner W, Eysholdt U (eds): Lehrbuch der Phoniatrie und Pädaudiologie. Stuttgart, Thiem, 2005, p 136.

23 Folstein M, Folstein S, McHugh P, Kessler J, Markowitsch H, Denzler P: Mini-MentalStatur-Test. Göttingen, Beltz Test, 2000.
24 Wuyts FL, De Bodt MS, Molenberghs G, Remacle M, Heylen L, Millet B, Van Lierde K, Raes J, Van de Heyning PH: The Dysphonia Severity Index: an objective measure of vocal quality based on a multiparameter approach. J Speech Lang Hear Res 2000;43: 796-809.

25 Seidner W, Eysholdt U: Diagnostik; in Wendler J, Seidner W, Eysholdt U (eds): Lehrbuch der Phoniatrie und Pädaudiologie. Stuttgart, Thieme, 2005, p 129.

-26 Maier A, Haderlein T, Eyshold U, Rosanowski F, Batliner A, Schuster M, Nöth E: PEAKS - a system for the automatic evaluation of voice and speech disorders. Speech Commun 2009;51:425-437.

27 Nawka T, Wirth G: Stimmstörungen: Für Ärzte, Logopäden, Sprachheilpädagogen und Sprechwissenschaftler. Köln, Deutscher Ärzteverlag, 2007, pp 177-178.

28 Münch R: Dialektik der Kommunikationsgesellschaft. Frankfurt am Main, Suhrkamp, 1992.

29 Lasswell HD: The structure and function of communication in society; in Bryson L (ed): The Communication of Ideas. New York, Harper and Brothers, 1948, pp 37-51.

30 Hakkesteegt MM, Brocaar MP, Wieringa $\mathrm{MH}$, Feenstra L: The relationship between perceptual evaluation and objective multiparametric evaluation of dysphonia severity. J Voice 2008;22:138-145.

31 Gonnermann U, Nawka T: Erfassung von Therapeieffekten auf die Stimme mit dem RBH-System, Dysphonie Schweregrad Index (DSI) und Voice Handicap Index-12 (VHI12); in Bose I (ed): Hallersche Schriften zur Sprechwissenschaft und Phonetik: Sprechwissenschaft. 100 Jahre Fachgeschichte an der Universität Halle. Frankfurt am Main, Peter Lang, 2007, pp 319-324.

32 Anders L, Evans R, Nawka T, Gonnermann U: 'Dysphonia Severity Index' and 'Voice Handicap Index' als semi-objektive und subjektive Dokumentationsmittel für Stimmstörungen. In press.

33 Awan SN, Roy N: Outcomes measurement in voice disorders: application of an acoustic index of dysphonia severity. J Speech Lang Hear Res 2009;52:482-499. 
34 Slingerland AS, Van Lenthe FJ, Jukema JW, Kamphuis CB, Looman C, Giskes K, Huisman M, Narajan KM, Mackenbach JP, Brug $\mathrm{J}$ : Aging, retirement, and changes in physical activity: prospective cohort findings from the GLOBE study. Am J Epidemiol 2007;166: 616-617.

35 Statistisches Bundesamt: Statistisches Jahrbuch 2008 für die Bundesrepublik Deutschland. Wiesbaden, Statistisches Bundesamt, 2008, p 44.

36 Behlau M, Hogikyan ND, Gasparini G: Quality of life and voice: study of a Brazilian population using the voice-related quality of life measure. Folia Phoniatr Logop 2007;59: 286-296.
37 Rasch T, Günther S, Hoppe U, Eysholdt U, Rosanowski F: Voice-related quality of life in organic and functional voice disorders. Logoped Phoniatr Vocol 2005;30:9-13.

38 Murry T, Medrado R, Hogikyan ND, Aviv JE: The relationship between ratings of voice quality and quality of life measures. J Voice 2004;18:183-192.

39 Grässl E, Hoppe U, Rosanowski F: Grading of the voice-related quality of life index (in German). HNO 2009;57:896-901.

40 Hakkesteegt MM, Brocaar MP, Wieringa $\mathrm{MH}$, Louw F: Influence of age and gender on the dysphonia severity index: a study of normative values. Folia Phoniatr Logop 2006;58: 264-273.
41 Jones S, Carding P, Drinnan M: Exploring the relationship between severity of dysphonia and voice-related quality of life. Clin Otolaryngol 2006;31:411-417.

42 Hummel C, Scharf M, Schützenberger A, Grässl E, Rosanowski F: Objective voice parameters and self-perceived handicap in dysphonia. In press.

43 Scharf M, Hummel C, Schützenberger A, Grässl E, Rosanowski F: Voice-related quality of life and perceptual voice analysis. In press. 